University of Wollongong

Research Online

Faculty of Social Sciences - Papers (Archive) Faculty of Arts, Social Sciences \& Humanities

2015

Effective practices for interagency data sharing: insights from collaborative research in a regional intervention

\author{
Pauline M. McGuirk \\ University of Wollongong, pmcguirk@uow.edu.au \\ Phillip O'Neill \\ Universty of Western Sydney \\ Kathleen Mee \\ University of Newcastle
}

Follow this and additional works at: https://ro.uow.edu.au/sspapers

Part of the Education Commons, and the Social and Behavioral Sciences Commons

Research Online is the open access institutional repository for the University of Wollongong. For further information contact the UOW Library: research-pubs@uow.edu.au 


\title{
Effective practices for interagency data sharing: insights from collaborative research in a regional intervention
}

\begin{abstract}
Data sharing adds considerable value to interagency programs that seek to tackle complex social problems. Yet data sharing is not easily enacted either technically or as a governance practice, especially considering the multiple forms of risk involved. This article presents insights from a successful data sharing project in a major region in east coast Australia involving a federally funded research partnership between two universities and a number of human services agencies. The Spatial Data Analysis Project sought to establish a community of practice for devising data sharing protocols and embedding data sharing into agency practices. Close dialogue between the project partners and mobilizing the authority of extant regulatory and legal frameworks proved effective in confronting risks and barriers. The article reveals effective practices for data sharing and derives lessons for other policy and governance contexts.
\end{abstract}

\section{Keywords}

regional, research, collaborative, insights, intervention, sharing, effective, data, interagency, practices

\section{Disciplines \\ Education | Social and Behavioral Sciences}

\section{Publication Details}

McGuirk, P. M., O'Neill, P. M. \& Mee, K. J. (2015). Effective practices for interagency data sharing: insights from collaborative research in a regional intervention. Australian Journal of Public Administration, 74 (2), 199-211. 
Pauline M M־uirk, Phillip M O’Neill, Kathleen J Mee

Effective Practices for interagency data-sharing: insights from collaborative research in a regional intervention

Corresponding author: Pauline $M M^{\mathrm{c}} \mathrm{Guirk}$

Centre for Urban and Regional Studies, Discipline of Geography and Environmental Studies, University of Newcastle, Callaghan, NSW 2308, Australia

Email: Pauline.mcguirk@newcastle.edu.au

Phillip M O’Neill, University of Western Sydney

p.oneill@uws.edu.au

Kathleen J Mee, University of Newcastle

Kathy.mee@newcastle.edu.au

Paper accepted: Australian Journal of Public Administration, 74, 199-211 
Effective practices for interagency data sharing: insights from collaborative research in a regional intervention

\begin{abstract}
Data sharing adds considerable value to interagency programs which seek to tackle complex social problems. Yet data sharing is not easily enacted either technically or as a governance practice, especially considering the multiple forms of risk involved. This paper presents insights from a successful data sharing project in a major region in east coast Australia involving a federally funded research partnership between two universities and a number of human services agencies. The Spatial Data Analysis Project sought to establish a community of practice so as to devise data sharing protocols and, simultaneously, to begin embedding data sharing into agency practices. Close dialogue between the project partners, and mobilising the authority of extant regulatory and legal frameworks, proved effective in confronting longstanding risks and barriers. The paper reveals effective practices for data sharing and derives lessons for other policy and governance contexts.
\end{abstract}

\title{
Key words
}

Data sharing, whole-of-government working, communities of practice, risk 


\section{Introduction}

The tangled nature of today's social problems routinely exposes public policy deficiencies and growing interest in whole-of-government approaches (Dawes et al., 2009; Ferlie et al., 2011; Keast, 2011). While analyses of the barriers to interagency working are plentiful (see Yang and Maxwell, 2011 for a review), strategies and practices for overcoming these barriers are limited (see Bellamy et al., 2008; Weitzman et al., 2006). One practice which attracts consistent interest is interagency data sharing. This paper reports on the implementation of an interagency data sharing project, known as the Spatial Data Analysis Project. The SDAP was a collaborative research project between human service agencies of the New South Wales (NSW) state government and university researchers. ${ }^{i}$

The SDAP sought to mobilise spatial data sharing and analysis as a way of enhancing human services delivery to address social vulnerability in the Hunter region, NSW (see $\mathrm{M}^{\mathrm{c}}$ Guirk and O’Neill, 2012). Our approach to the project, as the university researchers involved, was informed by three understandings. First, we would need a technical capacity that did not only show how diverse data systems could work together but one that could be built through negotiation among the parties involved, with openings for change and betterment as it was put to re-use. Second, the project's soft infrastructure would need to be integrated and reproducible in the practices of the project's user communities such that data sharing became normalised, with institutional and regulatory barriers modified from within. The third understanding was that interagency 'talk' would be crucial in driving both the establishment and operational phases of data sharing. Here the idea of 'communities of practice' (see Brown and Duguid, 1991) was important to us because it married practical insights with normative hopes.

Building from these understandings, SDAP's primary objective was to develop a framework process to guide data sharing practice and, through this process, to develop a suite of protocols and procedures which could navigate the institutional and regulatory barriers which have so often undone data sharing aspirations. Simultaneously, SDAP aimed to promote a culture of data sharing to support a more thorough-going whole-of-government habit around the practice of social governance. 
We discuss our approach and its enactment in the sections that follow. Section 2 scopes the key challenges to interagency working and data sharing and explores how the presence of multifaceted risk is a major barrier to projects like SDAP. In section 3 we set the Australian context for public sector data sharing before exploring the development and enactment of the SDAP process in section 4. In section 5 we assess the project and make some observations about what might be learned from the SDAP project, and then we draw some wider conclusions.

\section{Barriers to interagency working}

The benefits of interagency data sharing are widely recognised. They include resources efficiency and productivity; improved agency decision-making, responsiveness and flexibility; better service prioritisation and provision; and sharper policy evaluation (Agranoff, 2008; Gil-Garcia et al., 2007; Keast, 2010). Thus, data sharing has the potential to increase the capacity of governments to make progressive social interventions ( $\mathrm{M}^{\mathrm{\complement}} \mathrm{Guirk}$ and O’Neill 2012). Yet, a sizeable literature attests to the difficulties of government agencies acting collectively (Dawes et al., 2009; Fedorowicz et al., 2010; Gil-Garcia et al., 2007; Kwon and Feiock, 2010). At the outset we highlight one difficulty, the task of working together. For us resolving this difficulty is key. Keast notes that:

‘...(j)oined up working is not business as usual...it requires considerable adjustment to the ways in which organizations and people work together, as well as changes to current operating systems and process of participating agencies.' (Keast 2011; 229).

Joined-up working might alter existing work practices and flows, shift resources allocations, and change divisions of labour and responsibility. Such re-working might challenge agency hierarchies and cultures, require new communities of practice, and, therefore, new repertoires of competencies, routines and resources (see Wegner, 1998:73-85). Of course, constructing a cross-agency community of practice requires confronting those communities of practice protective of pre-existing ways of working and resources allocations. Not surprisingly, the process of constructing a cross-agency community of practice can incite resistance and subversion, including by bureaucratic frustration and compromise (Cowell and Martin, 2003; Dawes et al., 2009).

\section{Barriers to data sharing}


A vast, multidisciplinary literature chronicles the technical, organisational, institutional, and political obstacles to data sharing (e.g. Dawes et al., 2009; Gil-Garcia et al., 2007; Yang and Maxwell, 2011). A core message from the literature is that technical cleverness and ruledriven agreements will never be enough to overcome such obstacles (6 et al., 2006; Agranoff, 2008; Bellamy et al., 2008; Gil-Garcia et al., 2010; Lips et al., 2011; Weitzman et al., 2006). Resolving political and institutional obstacles requires an understanding of government agencies as sites of often-distinctive local knowledge, practices, habits and norms; which are bounded by fairly clearly marked political/policy territories; across a bumpy terrain of organisational values (Cowell and Martin, 2003: 163). Importantly, engineering the necessary shifts starts from recognising that interagency working is a social process involving 'sociotechnical interactions embodied in work processes, organizational forms and institutional contexts' (Dawes et al., 2009:401); that the complexity of these interactions emerges from the role played by information in public sector institutional practice; and that the 'business of talk’ (Boden 1994) is central to the development and circulation of information. Indeed, we see the business of talk as central to the construction and dissemination of an effective information-sharing project. But by 'talk' we mean complex talk involving dialogue around formal agreements, codified practices and informal relations, each of which will be overlain with statistical, legal, organisational and budgetary complexities.

\section{Data sharing as multi-faceted risk}

Entering conversations around interagency working, then, requires confronting multifaceted risk. Four inter-related risks are generally in play and require hedging. The first is the risk of unintended use which, at one level, includes concerns over data privacy, confidentiality and institutional exposure. At another level some see a need to guard against data re-analysis capable of producing alternative interpretations of performance or priorities (De Long and Fahey, 2000), or of raised public or political scrutiny (Clarkson et al., 2007). A common hedge, therefore, is the performance of 'information territorialism' (Slayton, 2000:12). A second risk arises when data are transferred outside the organisational culture responsible for their generation and custody. The missions, values and culture of an organisation shape its information portfolios (6 et al., 2005; Dawes et al., 2009). Consequently, organisations hold information within distinct categories, territorial boundaries and hierarchical structures, and often use bespoke metrics and outputs whose meanings do not always translate self-evidently 
(De Long and Fahey, 2000). In a multi-agency data environment, then, there is not just a risk of limited returns on substantial investment but also the possibility of negative returns due to misinterpretation and, even, data base disassembly (Lips et al., 2011, Dawes et al., 2009). Third, there is resources risk. Neoliberalised public sector management regimes demand direct links between resource allocations and outputs (Keast, 2010). Intra-agency turf battles over resources can generate suspicion of new programs, especially where these are not externally funded (Kwon and Feiock, 2010). There will be wariness over data-sharing initiatives with unproven or uncertain outcomes but which drain resources from other programs (Weitzman et al., 2006). A fourth risk is to organisational identity, something guarded jealously by most agency managers. Data sharing, by nature, involves modifying access to informational resources and patterns of knowledge distribution across an organisation, and rewriting long-established status and authority hierarchies (Bellamy and Taylor, 1996; Harvey and Tulloch, 2006, 748). Threats to agency discretion in policy and program decision-making arising from data-sharing can incite self-preservation instincts (Salmela and Turunen, 2003).

In summary, data sharing is a complex, messy and non-linear process; potentially, a 'jigsaw of conflict and cooperation' (Campbell, 1999: 627). It presents multiple risks to government managers whose response will probably involve 'informational rectitude’ (Bellamy and Taylor, 1996). Viewed this way the benefits of data sharing become clouded, meaning that enacting data sharing within the politically complex institutional environment of the public sector requires mediation in an intense form that recognises and addresses the risks that data sharing can bring.

In SDAP we explicitly sought to shape a process of engagement with data sharing-which we term a framework process - that could build a community of practice through which protocols and procedures to guide data sharing practice could be designed and embedded in participating agencies' practices. Existing research suggests that protocols and procedures alone are unlikely to mitigate the risks (and perceived risks) that hinder data sharing (Lips et al., 2011). A framework process that builds familiarity, trust, mutual purpose and dependency across a data-sharing community of practice, allows risks to be acknowledged and managed. 
In what follows, after a brief sketch of the Australian context, we work through the stages, elements and logics of SDAP's framework process, the resulting protocols and procedures, and the outcomes and lessons for data sharing in social governance.

\section{The Australian context}

Despite a history of attempts, large-scale information-sharing projects have not yet gained wide traction at state and federal level in Australia (AGIMO, 2011; 2009; 2006). Localised initiatives are more common, but knowledge of these is partial and their spread has been limited. In general, data sharing is more common in crime and health portfolios and less prevalent in community services (AGIMO 2009). Yet even as Australian commentators acknowledge the need for data sharing (e.g. PMSEIC 2006, and AGIMO, 2009), they identify there are risks in play, notably that privacy regulation in Australia is 'multilayered, fragmented and inconsistent' (Australian Law Reform Commission, 2008: 190); that information management practices do not readily align across agencies; that budgetary processes militate against proposals lacking clear and immediate value dividends; and that '....a culture of 'information is power'...results in the defensive protection of an organisation’s information assets' (AGIMO, 2009: 3).

As things stand, then, Australian government agencies largely operate within discrete informational territories (Keast, 2010) such that overcoming institutional barriers is the dominant challenge to data sharing. As the PMSEIC (2006, p.44) put it:

...as more organisations seek to use each other's data, agreeing on protocols for data access that can work between jurisdictions, sectors and discipline areas presents a complex problem... The different privacy and ethics regimes in the Commonwealth, States and Territories, varying policies relating to ethics at an institutional level and detailed considerations as to the possible identifiability of individuals within anonymised data all contribute to the difficulty in accessing data.

This is the context in which the Spatial Data Analysis Project evolved.

\section{The Spatial Data Analysis Project}


The Spatial Data Analysis Project (SDAP) was based in the Hunter region and its growing urban centres. In the early 2000s there was a rising perception that the region was witnessing an increased prevalence of socially vulnerable households with a growing stress on public sector resources. This led the regional office of the NSW Department of Premier and Cabinet (DPC) to prioritise a whole-of-government approach with plans for integrated social programs and improved resource efficiencies. The approach was to be advanced through the Regional Managers Network (RMN), an organisational innovation designed for coordination of the region's state government human service agencies. SDAP arose as a research collaboration between DPC, RMN and researchers from the University of Newcastle and University of Western Sydney'. Its broad objective was to advance the DPC's objectives through a multi-agency data sharing project involving the development of fine-grained spatial indicators for tracking social vulnerability. Because there were perceived geographical dimensions to the social vulnerability problem, SDAP's focus was deliberately spatial. Basic to the project would be the geo-coding of agencies' unit record data and their aggregation to Collectors District (CD) level, the smallest geographical area for which Australian Bureau of Statistics data are usually available. The analysis, to be delivered through a set of stylised indicators, maps and diagrams, would complement broader information and understandings held by the agencies thereby helping the delivery of better targeted services.

While the researchers had a successful history of providing the RMN with mapping and statistical services based mainly on census data, incorporating agency-held data required addressing the hindrances and risks discussed above. The paramount task for the collaborative engagement, then, was establishing a framework process and a reproducible set of protocols and procedures which could simultaneously build data-sharing communities of practice, sufficiently resolve organisational risk factors, and allow the involvement of academic researchers. This process became the SDAP.

Enacting the SDAP comprised two stages (Figure 1). The first involved designing and enacting a framework process to develop a data sharing culture, while the second involved negotiating and enacting a Memorandum of Agreement (MoA) to record the protocols which would guide and govern data sharing practices.

[FIGURE 1 HERE] 


\section{Stage 1: The SDAP framework process}

SDAP commenced with discussions among the agencies and their practitioner representatives via discussions based around the ways data sharing could contribute to specific problemsolving exercises. Our approach recognised data sharing as a non-linear, social process and, therefore, that a successful SDAP would more likely emerge through a context-specific framework rather than from abstract rule-systems (see Lips et al., 2011). A Reference Committee was formed comprising the academic researchers and representatives from the RMN and the participating agencies with a view to their becoming project champions. The Reference Committee operated as a forum to work through problems and forge common purposes (see Harvey and Tulloch, 2006).

Not accidently, the committee's first activity involved the business of talk: dialogue to draw out assumptions and expectations over SDAP's scope and purpose. Crucially, initial meetings not only clarified and defined the problems to which data sharing and indicator development would be applied, they allowed SDAP's approach to be fine-tuned to also seek data and indicators that agencies saw as meeting wider business demands; a flexibility found to contribute to the success of information sharing initiatives elsewhere (Bellamy et al., 2008; Keast, 2010). Building common purpose and understanding SDAP's longer term utility also contributed to allaying anxieties around unintended use of data, threats to the autonomy of agencies, and privacy and confidentiality issues (see Pardo et al., 2006, 6 et al. 2005). So the Reference Committee process also served as an important risk management strategy.

An early task of the Reference Committee was to propagate a shared data culture.

Discussions were held to identify agency data holdings, clarify data qualities, including data definitions and metadata characteristics, such that the nature and quality of each data set were revealed and criteria for data inclusion were clarified. Setting data quality standards provided the opportunity for agencies to clarify their own strategic data needs while building understanding of, and trust in, the data of others (see Haque, 2003). Discussion around the logics, institutional values, categorisations and interpretive frames embedded in agency data sets helped demystify the data sharing process. The dialogue and deliberation were also important in building the understanding of the university researchers. Importantly, the Reference Committee drew explicitly on the experience of local practitioners as situated agents to guide decisions about what and how to share, a process not easily enacted through 
abstract top-down rules (6 et al., 2006). Finally, stage one also enabled early identification of agency idiosyncrasies (e.g. an agency-specific ethics approval process) that would need to be addressed.

Together these initiatives secured the socio-technical alignment for data sharing (Martin, 2005). By moving first to establish a shared data culture, the Reference Committee was able to devise a set of formal protocols including rules for data sharing practices. Then discussion moved to the development of strategic applications of the SDAP output, and thereby securing agency buy-in. Importantly, then, the Reference Committee process enabled the formation of an epistemic community where agency concerns and interests overlapped (Agranoff, 2008). It also demonstrated, early in the life of the project, the benefits that would accrue to the missions of individual agencies as well as the broader benefits of a multi-agency approach. Understanding the benefits of SDAP aided negotiations around staffing and other resource commitments. Concerns about agency identity, autonomy and ownership were addressed, all as part of SDAP's business of talk. Through these activities participants gained confidence in the data collection, manipulation and analysis processes; while trusting relations were built between agencies and researchers. In turn, there was raised appreciation of the benefits of SDAP's anticipated outcomes. Our experience confirmed that while formal protocols are essential to successful data sharing, agreed-on understandings of appropriate behaviour are the real drivers of organisational life. Nonetheless, for durability, relational practices need to be embedded in formal mechanisms (Keast 2010, Ferlie et al. 2011), which we now discuss.

\section{Stage 2: Protocols and procedures}

The Reference Committee took on the task of devising a formal memorandum of agreement $(\mathrm{MoA})^{\mathrm{ii}}$ containing the protocols and procedures to govern data sharing practices. The MoA needed to express not just agreement to data sharing by the agencies but ways to address regulatory requirements, including federal and state privacy laws, and the research ethics frameworks of the agencies and the universities. The statement would also need to capture diverse agency requirements for confidentiality, ethics approvals, dissemination policies, and copyright issues. It would also need to describe procedures for secure, controlled and confidential sharing of data within the SDAP user group. Finally, it would need to be a readable, useable and persuading document. 
The success of the MoA development process underpinned its effectiveness as an operational instrument. Crucial to the success was joint activity between the researchers, the agencies, the universities' solicitors, the NSW Crown Solicitor, and the Office of the Privacy Commissioner NSW. As a first step, the researchers and representatives of the RMN met with the Office of the Privacy Commissioner met to discuss SDAP's intentions, establish its standing in relation to information privacy regulation, demonstrate likely outputs, and suggest protocols which might govern a complete SDAP product-cycle. After this meeting arrived at in-principle agreement on SDAP's approach, the MoA was drafted so as to flesh out and formalise the protocols. Important here were references to best practice guidelines (AGIMO 2006), advice on relevant legal frameworks, and agency input via the Reference Committee framework process. Thus the MoA (Figure 2) was able to outline SDAP's objectives, identify principals, describe the purpose of the data sharing, and then prescribe data handling procedures. These included procedures for: screening for data quality; encryption prior to data procurement and transfer; de-identification; processing and analysis; storing data and information; accessing and retrieving data; assigning data and information ownership; disseminating SDAP outputs; and disposing of data. In addition, the MoA laid out the responsibilities of agencies and researchers, and the controls over the publication of research outcomes. Finally, the MoA specified governance arrangements including for complaint resolution.

\section{[FIGURE 2 HERE]}

The roles played by the collaborators in drafting the MoA were crucial to its success. Close dialogue between researchers and RMN representatives on the Reference Committee generated a development agenda. The university solicitors ensured the legal obligations and interests of the researchers were addressed. The Crown Solicitor addressed the legal concerns of the agencies such as peculiarities in relation to regulations governing personal health data. Then the Office of the Privacy Commissioner provided a critical review commentary before approving the MoA as being in accord with relevant privacy legislation with an added (bonus) endorsement that, 'It is in the public interest for this worthwhile project to proceed' (Office of the Privacy Commissioner NSW, 10 ${ }^{\text {th }}$ Sept 2008).

Endorsement by agents external to the SDAP core-university and crown solicitors and, especially, the privacy commissioner-empowered the MoA as a processual instrument. Its 
presence considerably enhanced the authority of RMN representatives as they sought the participation of their agencies; and the MoA's content - detailed, yet plainly written provided advice on how to interpret and apply legal provisions, and on practical guidelines for data security, quality, manipulation and distribution. The MoA thus addressed the 'incomprehensibility’ of a legislative context (6 et al. 2006) that consistently frustrates data sharing exercises.

A comment on the role of the MoA in facilitating ethics approvals merits specific mention. Both university and agency ethics committees have strong traditions of concern around data privacy including the use of personal data without consent. Ethics committees are themselves communities of practice: they work in teams replete with value-laden, experience-driven interpretations of their regulatory frameworks. The research team's perception was that there was raised sensitivity to privacy issues within Hunter region institutions, and both agency and university ethics committees appeared wary that publicly-released government data might be used in ways that stigmatised communities and places. That the project's planned use of identifiable unit record data required the highest level of ethical review within Australia's NEAF (National Ethics Application Form) process added to the tension. Then the innovative and unusual nature of the research saw the researchers called to a special meeting with the chair of the university ethics committee to contextualise the project and present the case for substantial public benefit. Subsequently, the research partners were called to the university's ethics committee to discuss its concerns. In this process, the presence of the MoA - with its loaded-up authority - was important in assuaging doubts especially about privacy, especially from a legal perspective. The MoA provided evidence of well-thoughtthrough processes for minimising the risk of damage to individuals, communities and localities. In fact, SDAP's approach was judged to be exemplary, with ethics approval granted without the need for any substantial revision. Adding to the persuasive power of the MoA, the approved NEAF application ${ }^{\text {iii }}$ then became the basis for subsequent approvals from agency-based ethics committees. This had the flow-on effects of minimising SDAP transactions costs, maximising time and resources available to the project, and of generating a mood of success and goodwill across SDAP participants.

\section{SDAP outcomes and lessons}


The framework process, combined with the MoA and ethics approval process, codified the processes, protocols and procedures that enabled repositories of confidential data in the custody of government agencies to become available for data sharing under secure, controlled conditions. While the framework process commenced the dialogues through which to build relationships of trust and common purpose, the team's successful engagement with institutional systems of formal regulation ultimately gave the project authority and legitimacy (see 6 et al., 2006). The MoA - as endorsed by a thick layer of institutions - enabled public demonstration that the relevant protections were in place, the privacy laws were being met, and the process of sharing was covered by transparent guidelines (AGIMO 2009, 34). A first lesson is that both cultures of data sharing, embodied in a community of practice, and formally authorised technologies of regulation are important to managing the multifaceted risks of interagency data sharing.

For all the merits of the framework process, however, data sharing is still no more than an option within a portfolio of activities within an agency. So ease and efficiency of enactment are very important to its adoption (Harvey and Tulloch, 2006). Here, again, the MoA was important as it provided best-practice legal, technical, financial and political advice (Agranoff, 2008). Moreover the MoA was expressed in text that was easily understood. This text became an important counter to prejudices that had previously hampered data sharing efforts in the NSW public sector. A second lesson, then, is that embedding data sharing practices requires recognition of the over-filled action agenda of state agencies. Transparent, user-friendly protocols in which practitioners have confidence are needed to leverage the uptake of data sharing into the crowded routines of agency business.

MoAs were signed between the universities and departments responsible for housing; ageing and disability services; education; health, corrective services; police; the ambulance service; and fire brigades. Data were successfully delivered to the researchers with MoA conditions met by all participants. The research outcomes included a suite of fine-scaled indicators of social vulnerability and a series of major interpretive reports supplied to all participating agencies and to an extended group of agencies responsible for planning human services delivery. SDAP provided diagnostic tools, with re-constituted data, so that agencies could examine the compositional and geographical variability of vulnerability across the Hunter. More extensively, SDAP generated enabling, collaborative action around data sharing to build problem-resolution capacity and to organise interagency strategies for service delivery 
in novel ways. The DPC initiated whole-of-government interventions in a number of Hunter neighbourhoods, focused on the human services agencies involved in the project. As the potential of data sharing practices was realised, they began to be lightly embedded in agency practice. Agencies planned to use aspects of the reports to design interventions specifically to improve individual performance. Others began discussions about introducing new forms of data management to facilitate whole-of-government data sharing in the future. The data sharing process and outputs were used by agency representatives to demonstrate the support of evidence-based and whole of government practice by agencies in the Hunter region, and to apply for funds both from state and federal government sources. As discussion of the process and practices circulated across agencies, the research team was approached by other regional branches of DPC to discuss extending the processes developed in the Hunter and the possibilities for adapting them for implementation elsewhere. A final lesson, then, is that process and protocols together enable data sharing to begin to infiltrate the routines and practices of agency business and to become embedded in a manner that top-down, rule-based approaches alone are unlikely to achieve.

\section{Conclusion}

This paper provides a worked example of how to design and implement a process to address the multiple risks that have impeded data sharing among social services agencies. Based on learnings from the collaborative research, SDAP can provide a flexible template amenable to being adapted situationally and oriented to a particular problem-focus. The framework process was designed to address data sharing as a social process with a history of being shadowed by the tendency of agencies to contemplate data sharing as over-filled by risk. The effectiveness of the process came from being conscious of its positioning within the milieu of cultures and habituated practices within state agencies, such that close dialogue- the business of talk-was accommodated, indeed seen as essential, from the earliest stages. Focusing this dialogue around obvious and contingent problems and perceived risks, rather than abstract principles, allowed it to generate recognition of the benefits of data sharing and of possibilities for new data-use capacities, sufficient to assuage agency doubts and threats to norms and enculturated practices, information flows and status hierarchies. Thus the framework stage laid the foundations for a data sharing culture, common purpose and the development of a data sharing community of practice. 
Then, protocols and procedures arising from the MoA and ethics approvals formalised an institutional infrastructure within which to a community of practice was able to operate. Crucially, though, this infrastructure was not generated through top-down rules. It emerged through the framework process and so was widely accepted across the participating agencies as it addressed organisational realities: that negotiating regulatory conditions demands time and resources; that uncertainty and ambiguity mitigate user involvement; and that data sharing initiatives lose momentum without authoritative, written agreements to guide practice and manage tensions and concerns (6 et al., 2005). This infrastructure is what can provide longevity to data sharing innovations by allowing them to be integrated as ensembles of practices and rationales within existing user communities (Miller and Napier, 1993).

Finally, SDAP provides insights about nurturing a whole-of-government habit. Its approach created new capabilities with which to negotiate shared practices and outcomes, capabilities necessary to overcome the difficulty of enculturating whole-of-government practices where there are entrenched barriers and complex, messy, non-linear processes in play (Keast, 2010). In this sense, the framework process, protocols and procedures provide the architecture for a process of engagement between state agencies in all their institutional, cultural and motivational complexity with the potential to underpin broader interagency activity, build multi-agency communities of practice and support a whole-of-government habit. 


\section{Endnotes}

i The academic research team brought together ... (complete details on publication).

ii A full copy of the MoA is available from (website reference will be included for publication).

iii A full copy of the NEAF application is available from (website reference will be included for publication). 


\section{References}

6 ,P., Raab, C. and Bellamy, C. 2005. 'Joined-up government and privacy in the United Kingdom: managing tensions between data protection and social policy part 1' Public Administration 83:111-133

6 ,P., Bellamy, C., Raab, C., Warren, A. and Heeney, C. 2006. 'Institutional shaping of interagency working: managing tensions between collaborative working and client confidentiality’ Journal of Public Administration Research and Theory 17: 405-434

Agranoff, R. 2008. 'Enhancing performance through public sector networks' Public Performance \& Management Review 31: 320-347

Australian Government Information Management Office, 2011. 'Strategic Vision for the Australian Government's Use of ICT (Draft), Department of Finance and Regulation, Government of Australia, Canberra

Australian Government Information Management Office, 2009. ‘National Government Information Sharing Strategy’ Department of Finance and Regulation, Government of Australia, CanberrA

Australian Government Information Management Office, 2006. Australian Government Information Interoperability Framework. Department of Finance and Regulation, Government of Australia, Canberra

Australian Law Reform Commission, 2008. 'For Your Information: Australian Privacy Law and Practice. Australian Law Reform (ALRC Report 108)', Australian Government, Canberra) www.alrc.gov.au/publications/report-108

Bellamy, C., Taylor, J. 1996. 'New information and communications technologies and institutional changes: the case of the UK criminal justice system’ International Journal of Public Sector Management 9: 51-69

Bellamy, C., 6, P., Raab, C., Warren, A. and Heeney, C. 2008. 'Information-sharing and confidentiality in social policy: regulation multiagency working' Public Administration 86: 737-759

Boden, D. 1994. The Business of Talk: Organizations in Action, Polity Press, Cambridge Brown, J.S, and Duguid, P. 1991. 'Organizational learning and communities-of-practice: toward a unified view of working, learning and innovation' Organization Science 2: 40-57 Campbell, H., 1999. 'Institutional consequences of the use of GIS' In Geographical Information Systems eds P.A. Longley, M.G. Goodchild, D.J. Maguire, D. Rhind, John Wiley \& Sons, London, 621-31 
Clarkson, G., Jacobsen, T.E., and Batcheller, A.L. 2007. 'Information Asymmetry and information sharing’ Government Information Quarterly 24: 827-839

Cowell, R. and Martin, S. 2003. 'The joy of joining up: modes of integrating the local government modernisation agenda’ Environment and Planning C 21:159-79

Dawes, S., Cresswell, A., Pardo, T., 2009. 'From 'need to know' to 'need to share': tangled problems, information boundaries and the building of public sector knowledge networks' Public Administration Review, 69: 392-402

De Long D. and Fahey, L. 2000. 'Diagnosing cultural barriers to knowledge management' The Academy of Management Executive 14: 113-27

Fedorowicz, J., Gogan, J.L. and Culnan, M.J. 2010. 'Barriers to interorganizational information sharing in e-Government: a stakeholder analysis’ The Information Society 26: 315-329

Ferlie, E., Fitzgerald, L., McGivern, G., Dopson, S. and Bennett, C. 2011, 'Public policy networks and 'wicked’ problems: a nascent solution' Public Administration 89: 307-32

Gil-Garcia, R.J., Chengalur-Smith, I. and Duchess, P. 2007. 'Collaborative E-government: impediments and benefits of information-sharing projects in the public sector' European Journal of Information Systems 16: 121-133

Gil-Garcia, R.J., Pardo, T.A., and Burke, G.B. 2010. 'Conceptualizing information integration in government' in Electronic government: Information, technology, and transformation Ed HJ Scholl, ME Sharpe, Armonk, NY, 179-202

Haque, A. 2003. 'Information technology, GIS and democratic values: ethical implications for IT professionals in public service’ Ethics and Information Technology 5: 39-48

Harvey, F. and Tulloch, D. 2006. 'Local-government data sharing: evaluating the foundations of spatial data infrastructures' International Journal of Geographical Information Science 20: 743-68

Keast, R. 2011. 'Joined-up governance in Australia: how the past can inform the future' International Journal of Public Administration 34: 221-231

Kwon, S. ad Feiock, R.C. 2010. 'Overcoming the barriers to cooperation: intergovernmental service agreements’ Public Administration Review 70 : 876-884

Lips, A.M.B., O’Neill, R.R. and Eppel, E.A. 2011. ‘Cross-Agency collaboration in New Zealand: an empirical study of information sharing practices, enables and barriers in managing for shared social outcomes’ International Journal of Public Administration 34: 255-266 
Martin E, 2005, 'The data effect: sociotechnical interactions that align organisations with spatial data' paper presented to the Annual Conference of the Association of American Geographers, Denver

Mc Guirk, P.M. and O’Neill, P.M. 2012 ‘Critical geographies with the state: the problem of social vulnerability and the politics of engaged research’ Antipode 44: 1374-1394

Miller, P. 2001. 'Governing by numbers: why calculative practices matter' Social Research, 68: $379-396$

Miller, P. and Napier, C. 1993. ‘Genealogies of calculation’ Accounting, Organizations and Society 18: 631-647

Nedović-Budić, Z. and Pinto, J.K. 1999. 'Understanding interorganizational GIS activities: a conceptual framework, URISA Journal 11: 53-64

Pardo, T.A., Creswell, A.M., Thompson, F. and Zhang, J. 2006. 'Knowledge sharing in crossboundary information system development in the public sector. Information Technology and Management 74: 293-313

Prime Minister's Science, Engineering and Innovation Council. 2006. From Data to Wisdom: Pathways to Successful Data Management for Australian Science, Working Group on Data for Science, Australian Government, Canberra

Salmela, H. and Turunen, P. 2003. 'Competitive implications of information technology in the public sector: the case of a city geographical information system' International Journal of Public Sector Management 16: 8-26

Slayton, J. 2000. 'Establishing and Maintaining Interagency Information Sharing Juvenile Accountability Incentive Block Grants Program Bulletin, March, 1-16, www.pennsylvania.gov/portal/...0.../doc45_Slayton_2000.pdf

Wegner E, 2000, 'Communities of practice: the key to knowledge systems' in eds E Lesser, M Fontaine K Slusher Knowledge and Communities (Butterworth-Heinemann, Boston) pp $3-20$

Weitzman, B.C., Silver, D. and Brazill, C. 2006. 'Efforts to improve public policy and programs through data practice: experiences in 15 distressed American Cities’ Public Administration Review 66: 386-399

Yang, T.M. and Maxwell, T.A. 2011. 'Information-sharing in public organizations: a literature review of interpersonal, intra-organizational and inter-organizational success factors’ Government Information Quarterly 28: 164-175 
FIGURE 1: SDAP stages, purposes and outcomes

\section{STAGE 1: FRAMEWORK PROCESS $\rightarrow$ Create data sharing community of practice}

\section{Step 1}

Formation of reference committee

Step 2

Analysis of data holdings
- Establish vehicle for cross-agency 'talk' and dialogue

- Problem setting

- Delimitation of project scope and purpose

- Identify data holdings

- Identify internal agency requirements to release data

- Collectively interrogate data definitions, quality

- Collectively set data standards and criteria for data inclusion

- Discuss format of data outputs and strategic applications

- Scope possible protocols and procedures
- Identification of specific needs and expectations of individual agencies

- fine-tune project scope to individual agency demands

- Formation of common purpose

- Building confidence and commitment to the venture

- Identification of project champions

- Risk management

- Building shared data culture

- Creating common understanding and trust in each agency's data

- Fine-tuning data selection and outputs to agency needs

- Reaching agreement on data inclusions

- Socio-technical alignment

- Demonstrating benefits to generate agency commitment

- Securing agency resources to support project

- Building mutual dependencies amongst agencies

\section{STAGE 2: PROTOCOLS AND PROCEDURES $\rightarrow$ Embed data sharing practices}

\section{Step 1}

Consultation with relevant legal and privacy authorities

\section{Step 2}

Draft Memorandum of Agreement (MoA)

\section{Step 3}

Formalisation of MoA
- Obtain advice on intended protocols and procedures in light of privacy legislation and legal liabilities of all parties

- Scope alternative possibilities

- Maintain close collective dialogue with agencies

- Collectively refine and formalise protocols and procedures to govern data sharing practice

- Secure public endorsement of refined MoA from external agents

- Formalise agency sign-off on MoA
- Building agency confidence in capacity to meet legal/privacy regulation responsibilities in data sharing

- Risk management

- Addressing data confidentiality, privacy and security concerns

- Addressing legal and ethical regulation

- Determining dissemination issues

- Strengthening data sharing culture and agency commitment

- Solidifying management endorsement of data sharing

- Allaying anxieties about legislative context of data sharing

- Persuading practitioners

- Easing the process of obtaining ethics approvals

- Ease and efficiency of practice

- Embedding protocols and procedures in agency practices around data sharing 
FIGURE 2: Outline of MoA protocols

1. Conditions for agency supply of encrypted identified unit record data (including metadata)

- subject to agencies attaining necessary internal ethics approval prior to release
Receipt signed off by authorized data recipients
Access only by authorized project analysts who have signed confidentiality undertakings

Access only by authorized project analysts who have signed confidentiality undertakings

4. Conditions for:

- destruction of de-identified aggregated data on MoA expiry $O R$

- retention of de-identified aggregated data for research purposes subject to agency approval

5. Conditions for: - project governance

- reporting breaches of confidentiality

- conflict resolution

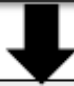

6. Appendix

Research Partnership Agreement specifying:

- funding arrangements

- joint ownership of project outputs by RMN and researchers

- ability of each party to use project outputs for research purposes

- permission to publish subject to review

by other party

Refer to SDAP Reference

Committee including

representation for all participating agencies
Partnership signed by RMN and universities 
